\title{
Juventude e consumo de notícias: comportamento geracional e hábitos culturais
}

\section{Carla Baiense Felix}

Professora do Departamento de Comunicação Social e do Programa de Pós-Graduação em Mídia e Cotidiano da Universidade Federal Fluminense (UFF). Coordenadora do Grupo de Pesquisa Mídias, redes e jovens: usos e apropriações em contextos digitais (CNPq/2014).

E-mail: carlabaienses@yahoo.com.br

\section{Larissa de Morais Ribeiro Mendes}

Professora do Departamento de Comunicação Social e do Programa de Pós-Graduação em Mídia e Cotidiano da Universidade Federal Fluminense (UFF). Filiada ao Grupo de Pesquisa Mídias, redes e jovens: usos e apropriações em contextos digitais (CNPq/2014).

E-mail: larissamorais@uol.com.br

\footnotetext{
Helen Pinto de Britto Fontes

Professora do Departamento de Comunicação Social da Universidade Federal Fluminense (UFF) e doutoranda no Programa de Pós-Graduação em Comunicação da Universidade do Estado do Rio de Janeiro (PPGCOM/UERJ). Filiada ao Grupo de Pesquisa Mídias, redes e jovens: usos e apropriações em contextos digitais (CNPq/2014). E-mail: brittofontes@gmail.com
}

\begin{abstract}
Resumo: Este artigo apresenta os resultados da pesquisa "Juventude, produção e consumo de notícias: novas dinâmicas, usos e apropriações". Analisamos os hábitos de 100 jovens entre 18 e 23 anos, pertencentes a dois grupos distintos: alunos do curso de Comunicação Social-Jornalismo, da Universidade Federal Fluminense, e estudantes do Pré-Universitário Popular. A análise buscou identificar a relação entre dados demográficos, hábitos de consumo e percepções, num ambiente marcado pela proliferação de conteúdos e dispositivos midiáticos. A especificidade da proposta está na investigação das formas de apropriação e consumo das notícias, um conceito, aliás, em transição, como analisamos. Buscou-se, ainda, estabelecer diferenças entre os comportamentos e crenças desse grupo etário, no que diz respeito à mídia, e dos demais extratos da população, mapeando o que seria um comportamento geracional.
\end{abstract}

Palavras-chave: Juventude; Consumo; Notícias; Cultura.

\section{Youth and news consumption: generational behavior and cultural habits}

Abstract: This article presents results of the research "Youth, production and consumption of news: new dynamics, uses and appropriations". We have analyzed the habits of 100 young people between 18 and 23 years of age, from two distinct groups: students of the Social Communication-Journalism course of Universidade Federal Fluminense, and students of Pré-Universitário Popular. The analysis has sought to identify the relationship between demographic data, consumption habits, and perceptions, in an environment marked by the proliferation of media content and devices. The specificity of this proposal lies in the investigation of news appropriation and consumption forms, a concept in transition, as we analyze. It has also sought to establish differences between behaviors and beliefs of this age group, regarding media, and of other extracts of population, by mapping what would be a generational behavior.

Keywords: Youth; Consumption; News; Culture. 


\section{Introdução}

A queda nas receitas publicitárias, junto com a redução das assinaturas, são as duas pontas visíveis do processo conhecido como a crise do impresso. A crescente onda de demissões nas redações reforça as suspeitas de que algo vai mal no mercado. De acordo com levantamento feito pelo Data Volt, em pouco mais de três anos (de 2012 a junho de 2015), 1.433 jornalistas foram demitidos dos grandes veículos brasileiros. Além disso, foram dispensados 5.205 funcionários de empresas de mídia nesse mesmo período para cortar custos.

Boa parte das explicações para a crise se concentra na percepção de que há uma migração de leitores e anunciantes para as plataformas digitais, não necessariamente para as empresas de mídia tradicionais. A entrada em cena de novas empresas como buscadores e redes sociais - estaria deslocando o lugar a partir do qual os leitores buscam informações e abalando os alicerces financeiros dos provedores tradicionais. Se em relação a um universo de leitores maduros, que se acostumou a ler o noticiário no papel, essa hipótese pode se confirmar, o que dizer a respeito dos novos leitores, que já cresceram conectados a plataformas digitais?

Neste artigo, apresentamos os resultados da primeira etapa da pesquisa "Juventude, produção e consumo de notícias: novas dinâmicas, usos e apropriações", realizada com apoio da Faperj (Auxílio Instalação Faperj/2014). Nela, procuramos analisar em que medida jovens estudantes da cidade de Niterói constituem um grupo específico em relação ao consumo de notícias, e de que modo variáveis como educação e renda têm impacto sobre seu comportamento, considerando o cotidiano midiatizado da cultura urbana contemporânea. Procuramos avaliar, ainda, o que os jovens consideram notícia atualmente, que critérios de confiabilidade das fontes estabelecem e de que maneira isso molda seu consumo.

Uma primeira consideração importante é em relação ao corte etário. Segundo o Conselho Nacional de Juventude, são jovens os indivíduos na faixa etária entre os 15 e os 29 anos. Consideramos, no entanto, que essa classificação não atenderia nossa proposta, tendo em vista a complexidade do conceito de juventude, sobretudo nos contextos latino-americano, de forma geral, e brasileiro, de modo particular, nos quais há uma clara distinção dos modos de ser jovem de acordo com a condição social, a região, o gênero, entre outras variáveis (MARGULIS; URRESTI, 1996; REGUILLO, 2013; MARTíN-BARBERO, 2002). Nas palavras da pesquisadora Rossana Reguillo:

La pobreza define en buena medida las biografías y trayectorias juveniles en muchos países y regiones del mundo; desempleo, precariedad, inseguridad y criminalización de la juventud y la pobreza, hacen parte de la experiencia cotidiana y subjetiva de millones de jóvenes. Con este panorama, al que podría añadir cifras terribles, no es difícil imaginar que la subjetividad está atravesada por el "desencanto". (SCOLARI, 2013)

${ }^{1}$ Em 2015, a compilação dos dados socioeconômicos dos calouros de 7 das 10 universidades mais bem colocadas no Ranking Universitário da Folha (RUF) levantou ainda que pouco mais de $40 \%$ dos estudantes vieram do ensino médio público, rede que atende a $87 \%$ dos alunos do país. Além disso, 27\% dos alunos dessas instituições são pretos ou pardos, enquanto a média da população é de $51 \%$, segundo o censo do IBGE (2010).
Considerando que o ingresso no mercado de trabalho representa, portanto, o início da vida adulta, em que os jovens perdem sua moratória social (MANNHEIM apud GROPPO, 2009), reduzimos a idade da amostra para o intervalo entre 18 e 23 anos, e consideramos como premissa para a seleção dos respondentes a ausência de vínculo trabalhista. Dessa forma, esperamos obter um universo mais "juvenil", no sentido atribuído por Margulis e Urrestis (1996).

Optamos, ainda, por analisar dois grupos distintos, tomando como critério o ingresso na universidade. Segundo um levantamento de 2015 da Folha de S.Paulo, nas dez melhores universidades do país, a taxa de alunos na faixa de renda mais baixa é de apenas $15 \%{ }^{1}$. Sendo assim, apesar dos avanços nos últimos anos, o perfil dos estudantes de faculdades públicas no país não espelha a diversidade da população jovem. Essa falta de representatividade de diferentes grupos nos levou a entrevistar estudantes que participam do Pré-Universitário Popular, um curso pré-vestibular mantido por professores e monitores da Universidade Federal 
${ }^{2}$ Agradecemos a gentileza dos coordenadores e alunos do Pré-Vestibular Popular, que funciona no Instituto de Engenharia da UFF, de nos receber e participar desta pesquisa.

${ }^{3}$ Ver, por exemplo, BAIENSE, C. F. et al, 2016.
Fluminense (UFF)², buscando analisar de que forma variáveis como educação e renda podem ter impactos sobre os hábitos e preferências de consumo midiático.

Na primeira etapa da pesquisa, desenvolvemos um questionário semiestruturado, com 47 perguntas, produzido no Google Forms e disponibilizado on-line. $\mathrm{O}$ questionário foi elaborado tendo em vista conjuntos de dados considerados relevantes para a análise, quais sejam: situação socioeconômica; acesso e utilização de diferentes tipos de produtos de mídia; acesso e utilização de diferentes tipos de tecnologias de comunicação e informação; acesso a notícias em diferentes tipos de mídia/suporte; preferências de uso, acesso e tipo de notícias (incluindo locais e plataformas); usos e apropriações da notícia em rede; confiabilidade de fontes de notícias.

O instrumento foi testado num grupo de controle, com indivíduos da mesma faixa etária da pesquisa, a fim de dirimir dúvidas e reformular questões mal compreendidas. Percebemos, por exemplo, a distinção entre informação e notícia para o grupo: informação pode se referir a quase tudo e se originar de qualquer fonte. Notícia, no entanto, é o que se enquadra na produção jornalística, de fonte formal ou não, mas obedecendo a determinados critérios (linguagem, apresentação, tema). Dessa forma, definimos em torno de "notícia" nossos questionamentos.

Os resultados obtidos na aplicação do questionário à primeira amostra - estudantes de graduação da UFF - já foram explorados em outros trabalhos ${ }^{3}$. Neste buscamos, a partir do conjunto de dados, vistos de forma comparativa, vislumbrar o que é comum, ou seja, geracional, na forma como a juventude se relaciona com a mídia em geral e com as notícias em particular, e o que é específico de grupos com diferenças de educação e renda. Em outras palavras, pretendemos, a partir da juventude e de sua forma particular de relacionar-se com a mídia e com o universo noticioso, captar as transformações na estrutura de sentimento do contemporâneo, tal como propõe Williams:

\begin{abstract}
Uma experiência social que está ainda em processo, com frequência não reconhecida como social, mas como privada, mas que na análise (e raramente de outro modo) tem suas características emergentes, relacionadoras e dominantes, e na verdade suas hierarquias específicas. Essas são, com frequência, mais reconhecíveis numa fase posterior, quando foram (como ocorre muitas vezes) formalizadas, classificadas e em muitos casos incorporadas às instituições e formações. (WILLIAMS, 1979, p. 134)
\end{abstract}

É esta reflexão, iniciada agora, que procuraremos aprofundar em outras etapas da pesquisa.

\section{Resultados}

De forma geral, confirmou-se a hipótese de haver um nível maior de educação e renda no núcleo familiar dos estudantes de graduação da UFF. Enquanto apenas $16,7 \%$ dos entrevistados nesse grupo afirmaram ter uma renda familiar de 1 a 3 salários mínimos, entre os estudantes de pré-vestibular 53,1\% se enquadram nessa faixa de rendimentos. Em relação ao nível de escolaridade do membro mais velho da família, $43,9 \%$ dos estudantes do primeiro grupo indicaram ser de nível superior, enquanto no segundo grupo, o percentual cai para $20,4 \%$. Perguntados sobre a presença de algum membro do núcleo familiar com nível superior, $72,6 \%$ dos primeiros entrevistados disseram havê-la. Já no outro grupo, de pré-vestibulandos, a presença cai para $42,9 \%$, e há ainda um percentual de famílias em que o membro mais velho não tem escolarização formal (6,3\%). Esse dado aponta para a relação entre escolaridade e renda, mas também para a configuração familiar dos estudantes. Embora a maior parte more com o pai (69\%) e a mãe (89\%), $18 \%$ ainda vivem com avô/avó. É justamente entre os idosos que se concentram os maiores índices de analfabetismo da população brasileira ${ }^{4}$.

\footnotetext{
${ }^{4}$ Segundo a Pesquisa Nacional por Amostra de Domicílios (PNAD) 2012, a taxa de analfabetismo tem sido maior nos grupos de idades mais elevadas. Enquanto a média nacional é de 11,9\%, entre a população de 60 anos ou mais é de $24,4 \%$.
} 
Os estudantes da UFF por sua vez, moram em sua maioria com pai $(54,5 \%)$ e mãe $(66,7 \%)$. Mas um percentual importante $(22,7 \%)$ também vive distante da família, revelando arranjos típicos da vida universitária (república, locação de vagas em casas de família), ou mesmo algum tipo de relação estável (companheiro/companheira), uma vez que nenhum entrevistado indicou que mora sozinho.

Reforçam as diferenças socioeconômicas o local de moradia dos entrevistados. Enquanto os graduandos da UFF se dividem entre os bairros do Rio de Janeiro e de Niterói, sendo que entre esses predominam os das áreas mais nobres da cidade, os demais moram, em sua maioria, em bairros e municípios periféricos em torno de Niterói. Há ainda uma pequena diferença em relação à idade nos dois grupos, com ligeira discrepância entre as faixas etárias majoritárias: no primeiro grupo predominam os entrevistados com 19 anos (28,8\%), enquanto no segundo a idade com maior representatividade é de 18 anos (40\%), revelando a força da moratória social no grupo com menor renda.

É contra esse pano de fundo que pudemos examinar as aproximações e distanciamentos em relação aos meios de informação, às plataformas de acesso ao noticiário e mesmo à predileção em relação ao formato da notícia. Embora lidando com o ambiente digital, os jovens ouvidos na UFF afirmaram, por exemplo, preferir o acesso às notícias sob a forma de texto $(89,4 \%)$, embora apareça um grande interesse no acesso via fotografia (59,1\%), vídeos (47\%) e infografia (33,3\%). A multimídia, linguagem nativa da rede, aparece em quinto lugar, com $27,3 \%$ das preferências. Quizzes, jogos e outros formatos totalizam 7,5\%.

Mesmo entre os jovens de menor escolaridade e renda predomina a predileção pelo formato textual, embora apareça um interesse maior pelos formatos audiovisuais. Nesse grupo, o texto permanece como linguagem preferida $(85,7 \%)$, seguido pelos vídeos e fotos (ambos com $61,2 \%$ das respostas), multimídia $(26,5 \%)$, infografias $(14,3 \%)$, jogos $(8,2 \%$ das respostas) e quizzes $(6,1 \%)$.

Não podemos determinar as causas para a predileção dos jovens por esse formato, mas é possível relacionar tal preferência com o capital simbólico das empresas de comunicação, sobretudo com a tradição dos jornais impressos; ou mesmo considerar que ao optarem por esse formato estariam buscando distinção (BOURDIEU, 2007), uma vez que a escrita, no Ocidente, tem maior valor cultural. $O$ fato é que, apesar de afirmarem a predileção pelo texto, não há uma tradução desse gosto no consumo de jornais. A leitura dos impressos em si está mais ligada à formação acadêmica e ao letramento do público, como se observa a partir dos dados.

Os jovens estudantes de jornalismo não apenas afirmam ter um contato frequente com os jornais - independentemente do suporte -, mas também se dizem familiarizados com a leitura de livros, estes predominantemente impressos. Os livros estão presentes em $83,3 \%$ das famílias desse grupo de entrevistados, e $63,7 \%$ afirmam ler mais de cinco livros por ano.

Relacionando os resultados de ambas as amostras, podemos afirmar que os que têm maior disponibilidade de livros em casa são também os que mais leem, o que vale tanto para livros quanto para jornais. No grupo do pré-vestibular, no qual predomina a posse de até 50 livros (51\%), a maior parte dos entrevistados lê até 5 volumes por ano $(61,2 \%)$. No outro extremo, entre os alunos da UFF, em que um percentual importante tem mais de 100 livros em casa (31,8\%), a maior parte dos respondentes costuma ler de 6 a 12 livros (37,9\%) por ano, sendo que outros 25,9\% leem mais de 12 , opção que não foi assinalada pelos alunos do pré-vestibular. Chama atenção, ainda, o alto percentual de entrevistados nesse grupo que marcou a resposta "não sei/NRA" (18,4\%), que contemplava as famílias que não possuíam livros paradidáticos.

$\mathrm{Na}$ leitura de jornais, a diferença entre os dois grupos pesquisados é ainda maior. Apenas $6,1 \%$ dos pré-vestibulandos leem jornais todos os dias, contra $25 \%$ no grupo dos estudantes de jornalismo. Os outros 75\%, no entanto, afirmam ler periódicos pelo menos alguns dias por semana. Ainda que a leitura seja predominantemente on-line $(66,7 \%)$, o jornal está presente de forma mais consistente no cotidiano dos jovens universitários. 
${ }^{5}$ Segundo o estudo, é entre os jovens dos 16 aos 25 anos que aparece o menor percentual de leitura de jornais impressos: $78 \%$ dos respondentes da pesquisa afirmam que nunca leram ou não leem jornais em nenhum dia da semana.
Já no grupo com menor escolaridade, destaca-se o percentual daqueles que dizem nunca ler jornal: 53,1\%. Apesar disso, o índice é menor que o apresentado pela Pesquisa Brasileira de Mídia 2014, da Secretaria de Comunicação Social da Presidência da República 5 . As assinaturas impressas todos os dias praticamente não existem entre os alunos do pré-vestibular ( $2,2 \%$ das respostas), mas ainda estão presentes na vida de $22,5 \%$ dos estudantes de jornalismo.

É curioso que o papel, suporte em declínio, supere os demais em relação à plataforma mais usada entre os pré-vestibulandos que leem jornal, tendo sido apontado por $30,6 \%$ dos jovens, seguido pelo suporte on-line $(28,6 \%)$ e pelos aplicativos (2\%). Já entre os estudantes de jornalismo há uma inversão, com o uso intensivo do recurso on-line, por $66,7 \%$ dos entrevistados, contra $13,6 \%$ da leitura em papel. A leitura on-line é bem maior no grupo no qual a leitura é mais intensa e frequente.

De modo geral, portanto, o cenário apontado pelos jovens revela que, mesmo nessa geração, há uma sobreposição entre leitura em papel e digital. Não apenas é mais intrínseca a relação entre os que leem com maior frequência (livros, jornais impressos) e os que leem notícias na internet, como também, para o grupo com maior escolaridade, não há uma clara diferenciação entre os variados suportes, uma vez que a convergência já se instalou na forma de se relacionar com as fontes de informação.

Já os jovens estudantes do pré-vestibular fazem uma diferenciação mais rígida entre os meios, ainda que reconheçam o pertencimento dos portais às mesmas empresas de comunicação que jornais e TVs. Neste caso, quando dizem jornal, se referem especificamente ao produto físico.

A preferência por jornais convencionais é notada em ambos os grupos: no grupo do pré-vestibular aparecem, por ordem de citação, O Globo (8 menções); Extra (5); $O$ Estado de S. Paulo (4); Folha, BBC, Lance! e O Fluminense (com 2 menções cada). Também foram citados Carta Capital, G1, Flipboard e Techmundo entre os pré-vestibulandos.

No grupo de graduandos, O Globo igualmente foi o mais citado (18 vezes), seguido da Folha de S. Paulo (6), O Dia (5), O Estado de S. Paulo (4), G1 (4) e Extra (4). Mas surgiram também menções a mais veículos fora do eixo da grande imprensa, como Pragmatismo Político (2 citações), O Cafezinho, El País, Caros Amigos e Piauí (todos com 1 citação). Os jornais Lance!, O Fluminense e Folha Dirigida também foram lembrados. Podemos dizer que, embora a leitura de jornais seja baixa entre os jovens, a imprensa convencional tem um espaço relevante nas suas preferências, inclusive em termos de credibilidade - como veremos a seguir.

Em relação à TV paga, há uma inversão (mas não na mesma proporção) dos resultados observados em relação a impressos, com $78,8 \%$ das famílias dos universitários dispondo do acesso a canais por assinatura, em comparação a $81,3 \%$ das famílias dos pré-vestibulandos. A TV é um meio muito importante para essa população - como veremos em outras questões -, e parece haver uma ligação entre a cultura predominantemente audiovisual e o nível de escolaridade/renda.

\section{Confiabilidade das fontes de notícias}

É interessante notar que a diferença em relação à presença dos impressos na vida dos jovens também se revela no nível de confiabilidade nos jornais das duas amostras. Quando perguntados sobre que tipo de fonte de informação consideram mais confiável, para a maior parte dos universitários a reposta é o jornal (45\%). Acreditamos não se tratar aqui simplesmente do jornal impresso (apenas duas respostas se referiam explicitamente a esse suporte), mas de veículos que mantém ou mantiveram versões impressas.

Já para o outro grupo, o jornal é citado em $2 \%$ das respostas. O que o percentual revela, mais que desconfiança, talvez seja desconhecimento ou distanciamento do produto. 
A TV é apontada por essa amostra em $20 \%$ dos casos como fonte mais confiável, percentual próximo ao citado pelos universitários (24,6\%). A diferença mais marcante se dá em relação à confiança na internet. Esta é citada tanto associada a portais (17\%) quanto de forma genérica (25\%), com uma frequência mais importante pelo grupo de estudantes de pré-vestibular (42\%) do que pelo grupo de graduandos (11,6\%).

Para os alunos de jornalismo, aliás, produtos nativos da internet - como blogs e redes sociais - se revelam como fontes de notícias menos confiáveis entre todas as outras. Os blogs aparecem em primeiro lugar, com $31 \%$ das respostas. Em seguida, vêm as redes sociais e os amigos/pessoas, que somados representam $11 \%$ das respostas. Podemos considerar, então, que, para $42 \%$ dos respondentes nesse grupo, notícias publicadas em canais desvinculados de grupos de comunicação têm menos confiabilidade que aquelas publicadas por grupos de mídia.

A partir disso talvez possamos interpretar a resposta dos jovens em relação às notícias que recebem através das redes sociais: $97 \%$ dizem ir sempre ou eventualmente à fonte da notícia. Embora nem sempre confiem no que é publicado nelas, são um importante ponto de contato com a informação.

Dessa maneira, podemos inferir que as redes sociais são quase sempre a porta de entrada a partir da qual os jovens ingressam no universo noticioso. Mas para eles é preciso confirmar a procedência - que nesse caso significa, ainda, confiabilidade - do que aparece na timeline. Os dados, portanto, confirmam a importância estratégica das redes para os veículos de comunicação e portais online. Ao mesmo tempo, revelam o poder simbólico dos grandes grupos midiáticos na produção de conteúdo noticioso.

Essa percepção é reiterada na questão sobre o compartilhamento da informação. Uma boa parte dos alunos da UFF não compartilha notícias a partir das redes sociais (40,9\%). Em relação aos que compartilham, 37,9\% o fazem a partir de sites, 36,4\% a partir de portais e $34,8 \%$ a partir da própria timeline - índice bastante alto, coerente com o fato de que os respondentes são estudantes de jornalismo que aprendem a buscar a informação na sua fonte original e a fazer sua checagem.

Pudemos observar que no pré-vestibular o percentual dos que compartilham direto da timeline é menor (26,5\%). Já outros 24,95\% compartilham a partir de sites e $32,7 \%$ a partir de portais. Uma boa parte dos alunos não compartilha: $38,8 \%$.

Na comparação entre as categorias de estudantes, verificamos a necessidade de aprofundar e entender melhor esses dados na próxima etapa qualitativa da pesquisa. Considerando que a presença de determinados conteúdos na timeline depende da própria relação que o indivíduo estabelece com sua rede social (calculada por um algoritmo), o menor percentual de compartilhamento entre os pré-vestibulandos pode indicar, por exemplo, que conteúdos noticiosos apareçam com menor frequência para esse grupo.

De fato, para esses entrevistados, as redes sociais aparecem como fonte de notícias em $69,4 \%$ das respostas, empatadas com os portais de notícias. Em seguida, vêm os sites de jornais $(61,2 \%)$, sites de revistas $(28,6 \%)$ e sites de TV $(24,5 \%)$.

Embora o grupo tome contato com noticiário via internet (de modo mais amplo) e a considere como meio confiável, revela uma preocupação menor em relação ao conteúdo noticioso que circula através dela. Parece que há entre esses jovens e as plataformas em rede (blogs, mídias sociais, sites noticiosos) uma relação diferente, voltada para outros tipos de aplicação (interação, pesquisa, busca de emprego, conhecimentos gerais). Isso se manifesta ao longo do questionário em alguns momentos, como no tipo de notícias que mais interessa (o que seria a rubrica "Cidade" quase não aparece, com um interesse maior em questões macropolíticas ou sociais) e na baixa citação das redes sociais como fonte confiável ou não confiável de informação.

Outra possibilidade para analisar essa relação é pensar até que ponto o conceito de notícia, para esse público, se vincula estritamente ao factual, ou obedece aos 
${ }^{6}$ Sob Sociedade agrupamos as matérias que tratam de questões políticas contemporâneas, mas não nos moldes tradicionais, como feminismo. valores-notícia tradicionais - como atualidade, ineditismo, proximidade. Talvez a notícia, nesse caso, se insira em outras lógicas, não captadas por esta pesquisa, a partir das quais os jovens recebem ou buscam informação especializada.

A fim de entender o nível de retenção ou atenção dada por ambos os grupos àquilo que leem nas redes, acrescentamos uma pergunta a respeito da última notícia recebida pelos entrevistados. A resposta mais ouvida entre os universitários foi "não me lembro/não consumi notícias", com $25 \%$ de menções. As outras respostas, no entanto, confirmam os tipos de notícia que mais despertam o interesse desses jovens: cidade/cotidiano, 16,6\%; esportes, 13,6\%; política, 13,6\%; cultura, 10,6\%; economia 7,5\%; internacional 7,5\%; e sociedade $6,4,5 \%$. Nesse sentido, a pesquisa reitera os formatos de notícia que mais circulam nos portais, ou seja, política/ economia/cidade. Mas revela, também, que o consumo se dá num nível muitas vezes superficial ou desfocado, um consumo difuso ou disperso, típico das múltiplas telas e da mobilidade.

\section{Bens, serviços e acesso a notícias}

Buscamos entender, a partir dos questionários, como é a relação de posse e utilização dos jovens em relação aos vários dispositivos midiáticos presentes no cotidiano e como se desenvolvem hábitos e protocolos de consumo em torno destes. Conforme se percebe, dispositivos mais antigos podem ter deixado de ter protagonismo nos lares, mas não desapareceram nem foram substituídos. Mesmo nas casas de graduandos da UFF, com renda e escolaridade maiores, onde as taxas de substituição de produtos tendem a ser maiores, notebooks e aparelhos de TV dividem praticamente o mesmo espaço, com percentuais de penetração bem próximos. Computadores de mesa têm menos importância, mas telefones fixos mantêm forte presença. Em relação a serviços, a assinatura de jornais e de TV paga é bem menor que a de internet. Mas não há dados que apontem para a diminuição, o aumento ou a manutenção dos níveis desses serviços.

Nas casas dos alunos de pré-vestibular, telefones fixos têm quase tanta importância quanto os celulares, em termos de penetração. Os livros são citados tanto quanto os computadores e mais que os notebooks. Os aparelhos de rádio aparecem mais que os tablets. As assinaturas de TV e jornal são a minoria, mas nada indica que tenha havido uma redução ou migração destas para plataformas digitais. É possível que, em relação aos jornais, por exemplo, seja mesmo um hábito cultural: o baixo índice de leitura ou a compra de exemplares avulsos - uma vez que a venda de jornais populares se dá em bancas, não por assinatura - não é um fenômeno novo, mas, ao contrário, aponta para uma continuidade.

Apesar da sobreposição de meios, em relação a fontes de notícia a internet assume o protagonismo, com $85 \%$ dos graduandos da UFF citando sites, portais, jornais on-line e redes sociais como sua fonte principal, e $11 \%$ indicando a TV. Em relação ao dispositivo, a TV tem importante presença, com 73\% das citações, o que revela uma característica interessante do público na relação com o meio. A discrepância entre as respostas dadas para "fonte" e "dispositivo" parece mostrar uma diferença qualitativa, e não necessariamente quantitativa, na interação dos jovens desse grupo com a TV. O telefone celular é apontado como dispositivo para acesso a notícias mais importante por ambas as amostras: $87,9 \%$ dos jovens do primeiro grupo e $79,6 \%$ do segundo.

A predileção pelo celular, no entanto, não significa uma escolha pela mobilidade, já que, em 75,7\% das respostas dos universitários, a casa é apontada como o lugar a partir do qual os jovens consomem notícias. As duas outras respostas mais citadas são a faculdade $(18,8 \%)$ e o estágio (19,6\%). Só 9\% dos entrevistados apontam a rua como local de acesso. $O$ uso do celular, portanto, associa-se a outras questões que podemos investigar, tanto de ordem financeira (custo) quanto de ordem cultural (privacidade, portabilidade) e tecnológica (linguagem).

A relação entre fonte de notícia e dispositivo de acesso mostra uma pequena diferença entre os dois grupos. Os alunos de pré-vestibular indicam a internet 
como principal fonte (69\%), seguida pela TV (34\%). O resultado é coerente com o dispositivo apontado - 79,6\% para TV, contra 76,6\% para celular -, ainda que revele uma desproporção. Embora a TV tenha um número de citações importante, não parece que desempenhe tamanho protagonismo no fornecimento de notícias. O uso simultâneo de dispositivos para consumo de notícias é indicado por 65,5\% dos entrevistados. As situações em que esse consumo se dá explicitam melhor o ambiente midiático em que os jovens se inserem: em casa, assistindo TV e checando o feed de notícias ou acessando outras redes sociais, estudando e fazendo pesquisas em diferentes dispositivos simultaneamente.

\section{A internet na vida dos jovens}

A análise dos questionários nos permitiu confirmar a impressão de que o acesso à internet figura como uma prioridade para jovens estudantes de diferentes camadas sociais, ao menos num centro urbano como Niterói. Entre os dois grupos pesquisados despontam diferenças quanto a meios e locais de acesso, usos e frequência de navegação, entre outras, mas não na concretização do acesso. Não há um único entrevistado que não use a internet, sendo o telefone o canal mais disponível e também o mais utilizado, muito à frente dos demais. $98 \%$ dos estudantes do prévestibular e $100 \%$ dos universitários dispõem de celulares em suas famílias para acesso à web. O acesso efetivo à rede através do celular é, respectivamente, de $85,7 \%$ e de $97 \%$. Provavelmente, a diferença para os $100 \%$ é relativa aos alunos que ainda não têm o próprio smartphone.

Atrás do celular, o notebook é o meio de acesso à internet mais presente entre as famílias, com 93,7\% de citações entre os universitários e de 71,4\% entre os alunos do pré-vestibular. No caso do computador, a disponibilidade é de $70 \%$ para ambos os grupos. O acesso à rede via tablets é de $43,9 \%$ e de $30,6 \%$, respectivamente. A explicação provável para a diferença está no maior poder aquisitivo dos estudantes de graduação.

A conexão à internet se dá, em primeiro lugar, a partir de redes wi-fi privadas, para os dois grupos, com percentuais de $87,8 \%$ entre os vestibulandos e de $98,5 \%$ entre os graduandos. Em seguida, no grupo do pré-vestibular, vêm 3G, wi-fi pública, 4G, cabo e 2G. Já entre os graduandos da UFF o acesso via $3 G$ supera o wi-fi público. Depois, a ordem de uso é a mesma.

A própria casa é o principal local de acesso para os dois grupos, e também o mais frequente. Entre os locais preferidos, de acordo com pergunta em que era necessário escolher uma opção apenas, a casa aparece como opção de 77,3\% dos graduandos e de $87,8 \%$ dos vestibulandos.

Possivelmente pela preocupação com segurança, associada ao fato de que muitos dependem de redes de wi-fi para estabelecer conexão, o acesso da rua é bem inferior, principalmente para o grupo de estudantes do pré-vestibular. Na pergunta com direito a múltiplas respostas, esse tipo de acesso foi marcado por $46,9 \%$ dos estudantes do cursinho e por $78,8 \%$ dos universitários, mas é o local mais frequente para somente $8,2 \%$ do primeiro grupo e $16,7 \%$ do segundo.

\section{As notícias via redes sociais}

Apesar dos cenários diversos, em que um grupo se prepara para entrar no universo acadêmico, enquanto o outro já está inserido nesse ambiente, os jovens já consolidaram o hábito de consumo de notícias via internet: 98,5\% dos universitários se informam através da rede, e estudantes pré-vestibulandos também possuem o mesmo hábito, com um índice pouco menor, de 91,8\%. Essa utilização massiva da internet para se informar antecipa a tendência apresentada também pelo brasileiro em geral. De acordo com a quarta edição da pesquisa Retratos da Leitura no Brasil, $52 \%$ dos perguntados usam a internet para ler notícias e informações em geral, dos quais $59 \%$ são jovens entre 14 e 18 anos. 
O acesso às notícias se dá principalmente pelo Facebook, seguido por Facebook e Twitter ao mesmo tempo. Embora sejam do curso de jornalismo e tenham acesso a produtos específicos da ordem da produção de notícias e conteúdo, além de meios de comunicação diversos, os estudantes pesquisados se informam apenas pelo Facebook, em 40,90\% dos casos, e pelo Facebook e pelo Twitter juntos, em $31,81 \%$ das respostas. Os alunos de pré-vestibular que usam de forma conjunta o Facebook e o Twitter para as notícias são $32,25 \%$, seguidos pelos que, além dessas duas, incluem o Instagram $(16,12 \%)$ e por aqueles que só as acessam através do Facebook (12,9\%).

O resultado nos chama atenção uma vez que os estudantes se preparam para uma formação que privilegie investigações e buscas pela informação isenta, através de atitudes inovadoras e fora do senso comum, em prol da construção do pensamento crítico. Num primeiro momento, faz-nos pensar o fato de estudantes de jornalismo se satisfazerem somente com esta fonte, o Facebook, que é replicadora e intermediadora de outros sites. O futuro jornalista está com acesso às notícias num contexto mais "limitado" e se satisfaz com isso, sem apurar mais detalhadamente a informação recebida.

Talvez, pela grande oferta de informações diversas e irrestritas, o hábito diferenciado seja o de ir até o site de origem para ler e se aprofundar nas informações, mas o cenário apontado carece de maior investigação. A maioria dos futuros formadores de opinião apontaram que têm tal atitude às vezes $(51,5 \%)$, contra $45,5 \%$ que vão sempre até o site de origem. A permanência na timeline também acontece entre os que se preparam para entrar na graduação, quase na mesma proporção: 53,1\% o fazem às vezes, contra $32,7 \%$ que sempre seguem para a fonte de informação.

De maneira geral, tais dados mostram que, apesar de o acesso às notícias ocorrer inicialmente através das redes sociais, os jovens não as enxergam como canal confiável e, por isso, não compartilham as informações diretamente, ou, se compartilham, o fazem depois de irem aos sites originais da informação.

Um bom tempo de conexão é dedicado ao acesso a notícias: de 30 minutos a 1 hora, por $42,4 \%$ dos respondentes universitários, e de 1 a 3 horas, por $34,8 \%$ deles. O percentual utilizado da conexão para notícias também indica essa relevância: $43,9 \%$ dos pesquisados dedicam até $30 \%$ dela, enquanto $34,8 \%$ utilizam de $30 \%$ a $50 \%$. Entre os pré-vestibulandos, a notícia ocupa um tempo menor da conexão: $51 \%$ dos estudantes permanecem de 30 minutos a 1 hora em contato com noticiário, e 18, $4 \%$ ficam de 1 a 3 horas dedicados ao acesso. Em termos percentuais de conexão, $42,9 \%$ dos que se preparam para o vestibular gastam até $30 \%$ desta, enquanto $28,6 \%$ utilizam de $30 \%$ a $50 \%$, e $20,4 \%$ dos respondentes utilizam menos de $10 \%$ da conexão em busca de notícias.

Tais dados apontam que já existe um olhar mais atento às notícias e, consequentemente, ao jornalismo, mesmo antes de o jovem amadurecer intelectual e profissionalmente. Num primeiro momento, podemos pensar na busca por essas informações apenas como ferramenta para a realização de uma boa prova. Mas nossa reflexão torna-se mais abrangente ao olharmos mais de perto para os índices dos que vão em busca da informação em suas fontes de origem, como portais e sites de informação.

\section{Considerações finais}

Numa análise a respeito da disponibilidade de meios de acesso, fica clara a hipermidiatização do cotidiano dos jovens entrevistados, independentemente da sua classe social. Da mesma forma, percebemos uma intensa exposição ao noticiário. Através de várias plataformas e dispositivos, os jovens acessam, espontânea ou casualmente, um universo de notícias muito maior que o das gerações anteriores.

A circulação de informações tende a ser maior entre os grupos com renda e escolaridade maiores, incluindo aí a escolaridade dos membros da moradia. 0 fato de haver um número maior de dispositivos conectados à rede nas famílias 
dos extratos mais abastados, o maior tempo de conexão e a diversidade de formas de acesso a notícias, incluindo jornais diários e TVs por assinatura, indicam um ambiente com maior disponibilidade de informação.

De modo geral, o cenário apontado pelos jovens da UFF revela que há uma relação entre os que leem com maior frequência (livros, jornais impressos) e os que leem mais notícias na internet. Da mesma forma, mostra que o jornal, para este público, já não se liga exclusivamente ao seu suporte, levando para a internet suas propriedades, como a confiabilidade.

Parece que os jovens do pré-vestibular fazem uma diferenciação mais rígida entre os meios, ainda que reconheçam o pertencimento dos portais às mesmas empresas de comunicação que jornais e TVs. Nesse caso, quando dizem jornal, referem-se especificamente ao produto físico.

Quando os alunos da UFF apontam uma baixa utilização da TV como fonte de notícia, de maneira desproporcional ao uso da TV enquanto dispositivo de acesso a noticiários, talvez eles estejam indicando uma mudança qualitativa em relação à credibilidade do noticiário produzido pelos canais televisivos. Ainda que acessem notícias por meio das TVs, não é a partir delas que se "informam" verdadeiramente - apesar de a maioria das citações se referir a portais e sites de notícias controlados pelos mesmos meios de comunicação que controlam as emissoras.

A mesma incongruência é apontada pelos estudantes quando consideram os jornais como fontes de notícia mais confiáveis, a despeito de sua filiação aos mesmos grupos de comunicação que controlam sites, emissoras de rádio e TV. Ao que parece, o formato noticioso, em certa medida, condiciona a credibilidade da informação. Os estudantes de jornalismo são também naturalmente mais críticos em relação à confiabilidade das redes, em relação ao segundo grupo. Não é possível associar esses dados simplesmente a um aumento de renda e escolaridade, tampouco desprezar o fato de que estudantes de jornalismo recebem uma formação mais crítica em relação ao que circula nas redes. De todo modo, as diferenças em relação ao nível de confiabilidade encontradas entre os jovens mostram que os fatores geracionais influenciaram, sem dúvida, o hábito em relação ao consumo de notícias, mas ainda não alteraram as crenças e a escala de valores quando se trata de confiabilidade.

Embora ainda se careça do aprofundamento que pretendemos fazer em etapas posteriores da pesquisa, podemos perceber, preliminarmente, duas forças distintas, e não necessariamente antagônicas, operando no consumo noticioso dos jovens: por um lado, o papel da tradição, expresso na predileção pelo formato impresso, na confiabilidade dos jornais e na escolha das fontes de notícias. Por outro, a convergência, que dilui diferenças rígidas entre suportes, meios e mídias. São tendências que moldam os hábitos, usos e apropriações em ambientes digitais e que revelam caminhos para o desenvolvimento de novas relações com as audiências.

\section{Referências}

BAIENSE, C. F. et al. Confiança e consumo da mídia impressa entre jovens: apontamentos a partir da Pesquisa Brasileira de Mídia. Mediação, Belo Horizonte, v. 18, n. 22, jan./jun. 2016.

. O futuro do jornalismo: como os estudantes da UFF consomem notícias. In: XXXVIII Congresso Brasileiro de Ciências da Comunicação, 2016, São Paulo. Anais.... São Paulo: Intercom, 2016.

BRASIL. Presidência da República. Secretaria de Comunicação Social. Pesquisa Brasileira de Mídia, 2015: hábitos de consumo de mídia pela população brasileira. Brasília: Secom, 2014a. Disponível em: <https://bit.ly/1FAvjZC>. Acesso em: 10 jun. 2016.

BOURDIEU, P. O capital social - Notas provisórias. In: CATANI, A.; NOGUEIRA, M. A. (Orgs.). Escritos de educação. Petrópolis: Vozes, 1998. 
. A economia das trocas simbólicas. São Paulo: Perspectiva, 2007.

BRASIL. PNAD 2012: Cai o percentual de pessoas sem instrução. Portal Brasil, 27 set. 2013. Disponível em: <https://goo.gl/o5tfLi>. Acesso em: 28 maio 2017.

GROPPO, L. A. O funcionalismo e a tese da moratória social na análise das rebeldias juvenis. Estudos de Sociologia, Araraquara, v. 14, n. 26, p. 37-50, 2009.

INSTITUTO PRÓ-LIVRO. Pesquisa Retratos da Leitura no Brasil, 4a edição. São Paulo: Instituto Pró-Livro, 2016. Disponível em: <https://bit.ly/2w2593W>. Acesso em: 1 jul. 2016.

MARGULIS, M.; URRESTI, M. La juventud es más que una palabra. In: MARGULIS, M. (Org.). La juventud es más que una palabra. Buenos Aires: Biblos, 1996.

MARTíN-BARBERO, J. América Latina e os anos recentes: o estudo da recepção em comunicação social. In: SOUSA, M. W. (Org.). Sujeito, o lado oculto do receptor. São Paulo: Brasiliense, 2002.

- Ofício de cartógrafo. Travessias latino-americanas da comunicação na cultura. São Paulo: Loyola, 2004.

PORTO, W. Estudante típico das 10 melhores está distante da média brasileira. Folha de S.Paulo, São Paulo, 14 set. 2015. Disponível em: 〈https://goo.gl/xwwa2s>. Acesso em: 9 set. 2016.

SCOLARI, C. A. Ser joven nunca fue fácil. Entrevista a Rossana Reguillo. [S.I.: s.n.], 2013. Disponível em: <https://bit.ly/1hPdjLQ>. Acesso em: 6 abr. 2018.

VOLT DATA. A Conta do Passaralho. Disponível em: <https://goo.gl/jsuAVy>. Acesso em: 9 set. 2016.

WILLIAMS, R. Marxismo e literatura. Trad. Waltensir Dutra. Rio de Janeiro: Zahar, 1979. 